\title{
Sub-acute occupational hypersensitivity pneumonitis due to low-level exposure to diisocyanates in a secretary
}

\author{
J. Schreiber*, J. Knolle*, J. Sennekamp『, K.T. Schulz*, J.U. Hahn+, K.G. Hering ${ }^{\S}$, \\ M. Raulf-Heimsoth ${ }^{f}$ and R. Merget ${ }^{f}$
}

ABSTRACT: There is virtually no information in the literature about the exposure levels needed to induce hypersensitivity pneumonitis (HP) by diisocyanates. The present study reports a case of occupational HP due to diisocyanates after low-level exposure.

A 53-yr-old female never-smoker developed progressive shortness of breath on exertion, cough, fatigue and flu-like symptoms shortly after she began work as a secretary of a car body repair shop. A diagnosis of HP was made 2 yrs later, based on a restrictive ventilatory defect, a reticulonodular and discrete ground-glass pattern on high-resolution computed tomography, lymphocytosis in bronchoalveolar lavage and specific immunoglobulin $G$ antibodies to diisocyanate human serum albumin conjugates in the patient's serum.

The diagnosis was confirmed by recovery after exposure cessation and deterioration after reexposure. Ambient monitoring revealed air concentrations of different diisocyanate monomers below the detection limit in both the patient's work station and in front of the paint spray booths, with the exception of one measurement that showed 4,4-methylenediphenyl diisocyanate concentrations of $3 \mu \mathrm{g} \cdot \mathrm{m}^{-3}$ in front of one booth (corresponding to a total reactive isocyanate group concentration of $1 \mu \mathrm{g} \cdot \mathrm{m}^{-3}$ ).

The present authors conclude that concentrations of disocyanates far below current exposure limits may induce hypersensitivity pneumonitis in susceptible subjects.

\section{KEYWORDS: Diisocyanates, hypersensitivity pneumonitis, occupational exposure}

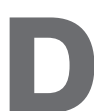

iisocyanates are the most important single cause of occupational asthma in many countries [1]. While asthma is the most prominent disease, hypersensitivity pneumonitis (HP) induced by diisocyanates has been reported casually [2], but recent information suggests that in some workplaces, HP may be a more frequent consequence of diisocyanate exposure than originally thought [3]. Little is known about the exposure levels needed for the induction of HP by diisocyanates; one epidemiological study in a plant engineered for minimal exposure to diisocyanates did not report cases suggestive of HP [4]. A recent expert workshop concluded that data regarding dose-response relationships of diisocyanates on primary sensitisation are few and insufficient [1], this is particularly the case for HP.

\section{CASE REPORT}

A 53-yr-old female, nonatopic never-smoker had worked intermittently as a secretary of a car body repair shop since March 1999 and had been in regular employment until April 2000. The patient was otherwise healthy and was not taking any medication. She developed shortness of breath on exertion, cough, phlegm production, fatigue and nightly fever shortly after starting the job. In 2000, the symptoms progressed rapidly. These symptoms had a slowly progressive course, with no direct relationship to work, but did improve when the patient was on holiday. She had no prior or concomitant nonoccupational contact to diisocyanates or other known inducers of HP. In January 2002, the symptoms worsened and she quit work in April 2002 (fig. 1). A diagnosis of HP was made shortly afterwards in April/May 2002, 3 yrs after the start of exposure. Auscultation yielded highfrequency end-inspiratory crackles in both lungs. A chest radiograph and a computed tomography (CT) scan showed discrete ill-defined centrilobular nodules, as well as a patchy ground-glass pattern (figs 2 and 3).

\section{AFFILIATIONS}

*Dept for Pneumonology, Otto-vonGuericke-University, Magdeburg,

\#Institute of Pathology, Municipal Hospital Dessau, Dessau,

"Institute of Lung Diseases and Allergy, Malteserträgergesellschaft, Bonn,

${ }^{+}$BGIA, Institute for Occupational Safety and Health, German Social Accident Insurance, Sankt Augustin,

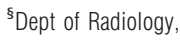

Knappschaftskrankenhaus, Dortmund, and

${ }^{f} \mathrm{BGFA}$, Research Institute of Occupational Medicine, German Social Accident Insurance, Ruhr University, Bochum, Germany

CORRESPONDENCE

J. Schreiber

Dept for Pneumonology

Otto-von-Guericke-University

Leipziger Str. 44

D-39120 Magdeburg

Germany

Fax: 493916793356

E-mail: jens.schreiber@

medizin.uni-magdeburg.de

Received:

May 172007

Accepted after revision:

February 132008

STATEMENT OF INTEREST

None declared.

European Respiratory Journal Print ISSN 0903-1936 Online ISSN 1399-3003 


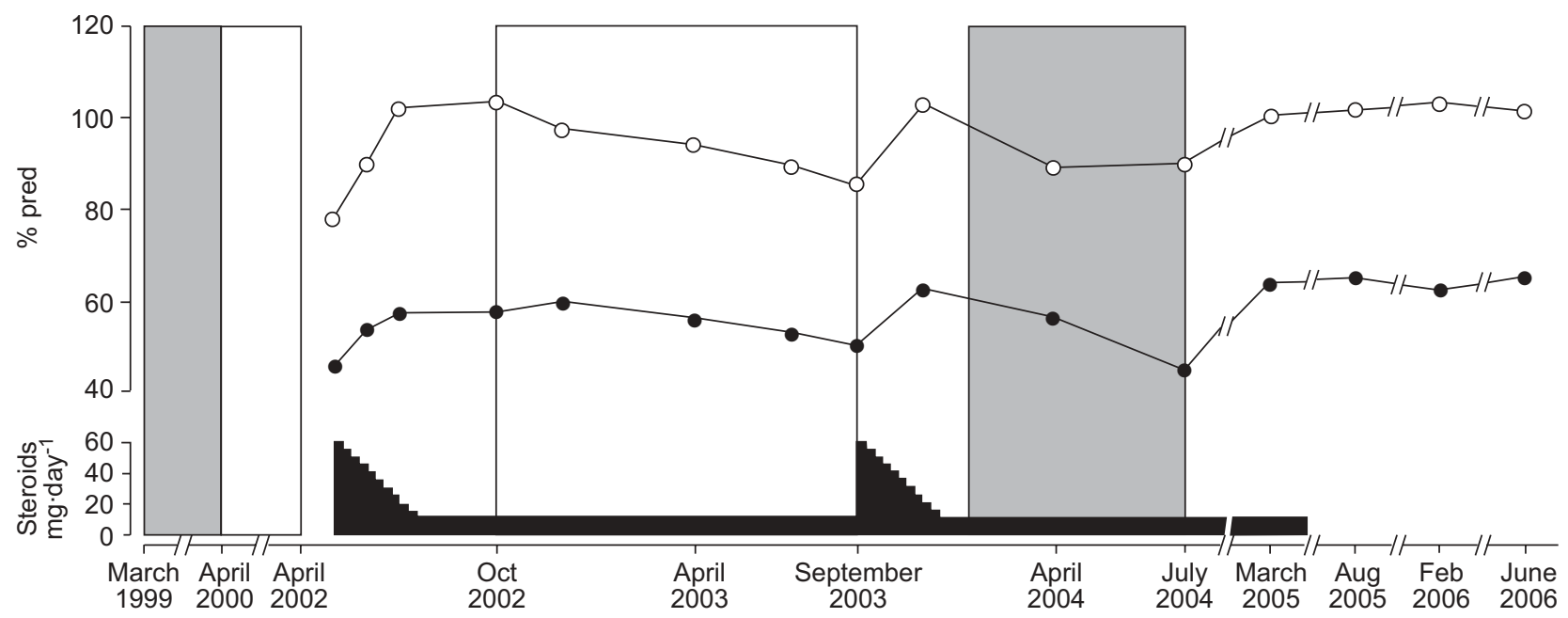

FIGURE 1. Time-course of exposure, treatment with oral prednisolone $(\boldsymbol{\square})$ and lung function. $\bigcirc$ : vital capacity (\% predicted); unit of alveolar volume as assessed by the single breath method; $\square$ : regular re-exposure; 1 : intermittent re-exposure.

In the patient's serum, elevated specific immunoglobulin (Ig) $G$ antibodies were found to 2,4'-toluene diisocyanate (TDI; $42 \mathrm{mg} \cdot \mathrm{L}^{-1}$ ), 4,4'-methylenediphenyl diisocyanate (MDI; $\left.62 \mathrm{mg} \cdot \mathrm{L}^{-1}\right)$, and 1,6-hexamethylene diisocyanate (HDI; $87 \mathrm{mg}^{-\mathrm{L}^{-1}}$; all ImmunoCAP; Phadia, Freiburg, Germany); the cut-off for increased concentrations using this method was $20 \mathrm{mg} \cdot \mathrm{L}^{-1}$. IgG antibodies to other antigens known to cause HP were not found, e.g. various mould species and acid anhydrides. As there was no contact with birds, IgG antibodies to bird antigens were not determined. $\mathrm{IgE}$ antibodies to diisocyanates (again using the ImmunoCAP system) were absent.

Pulmonary function testing showed a mild restrictive pattern (vital capacity (VC) 75.7\% predicted, total lung capacity (TLC) $82.0 \%$ pred; reference values of European Coal and Steel Community) [5] and a reduction of the diffusing capacity of the lung for carbon monoxide per unit of alveolar volume as assessed by the single breath method ( $\mathrm{DL}, \mathrm{CO} / \mathrm{VA} 46.5 \%$ pred) without obstruction. Arterial oxygen tension $\left(\mathrm{Pa}_{2} \mathrm{O}_{2}\right)$ fell from 65 to $43 \mathrm{mmHg}$ after a treadmill exercise up to $65 \mathrm{~W}$.
Bronchoalveolar lavage (BAL) showed a total cell count of $2.0 \times 10^{5}$ cells $\cdot \mathrm{mL}^{-1}$ (recovery $130 \mathrm{~mL}$ ) with $81 \%$ lymphocytes, $17 \%$ macrophages, $2 \%$ neutrophils and a CD4/CD8 ratio of 0.1 . The histological examination of transbronchial lung biopsies yielded infiltration of the alveolar septa with lymphocytes, histiocytes and scarce plasma cells, as well as desquamation of pneumocytes and filling of the alveoli by macrophages, but no granuloma formation (data not shown). A diagnosis of subacute occupational HP due to diisocyanates was made.

\section{Follow-up}

The patient was treated with prednisolone $1 \mathrm{mg} \cdot \mathrm{kg}^{-1}$ for 4 weeks. After this time, the dose was tapered to $10 \mathrm{mg}$. This treatment led to significant functional improvement although complete recovery was not achieved (fig. 1). By maintaining treatment with prednisolone $\left(10 \mathrm{mg} \cdot \mathrm{day}^{-1}\right)$ the patient resumed employment, by her own decision, in October 2002. This led to a progressive deterioration in the patient's health until September 2003 (fig. 1). In July 2003, isocyanate-specific IgG antibodies were found to be slightly higher, similar to the time of diagnosis (TDI: $43 \mathrm{mg} \cdot \mathrm{L}^{-1}$;
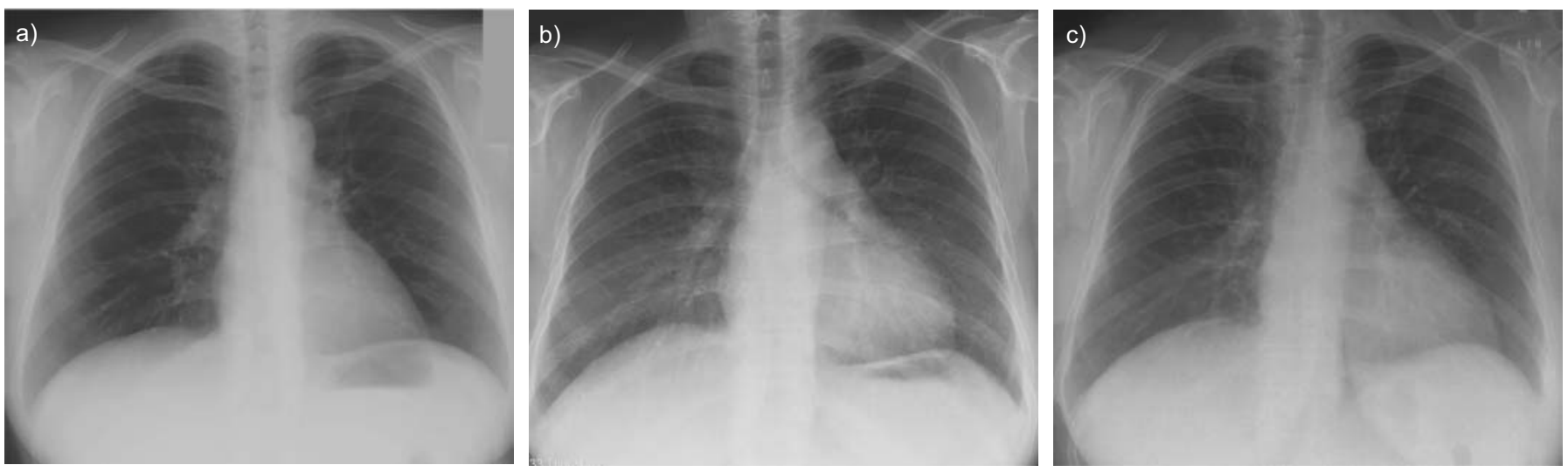

FIGURE 2. Chest radiographs of the patient were normal in a) November 1999 (soon after the occurrence of initial symptoms). b) In May 2002, bilateral subtle ill-defined parenchymal opacities with middle and lower lung preponderance was documented. c) The radiograph taken in June 2006 was considered normal. 

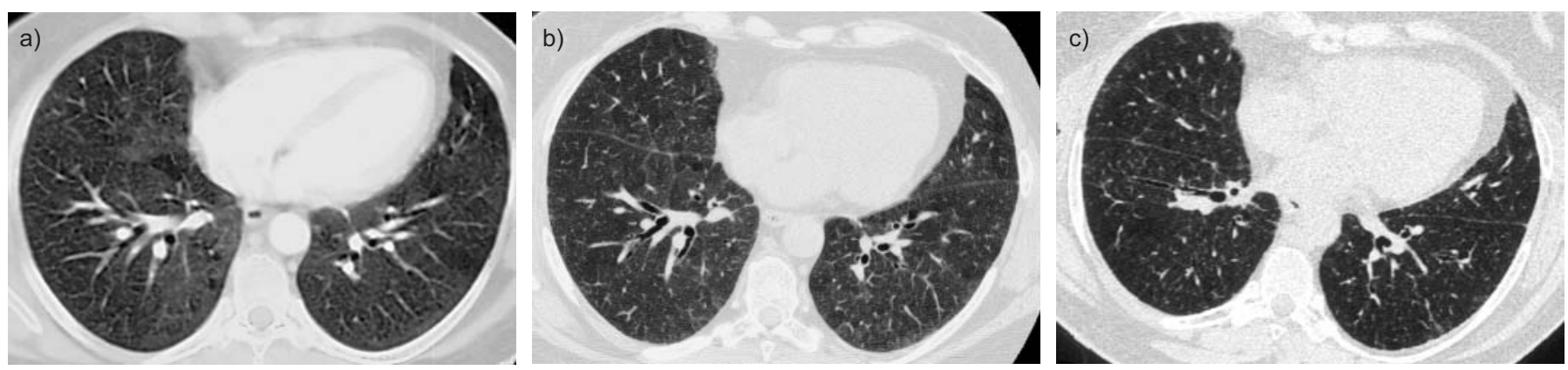

FIGURE 3. a) A computed tomography (CT) scan taken in April 2002 showed discrete ill-defined centrilobular nodules and a patchy ground-glass pattern. This finding was also present, but less pronounced, on a high-resolution CT scan in November 2003 (b). c) In October 2004, another high-resolution CT scan documented further improvement, but there were still ill-defined centrilobular opacities with preponderance in the apical lung fields and discrete patchy ground-glass pattern in the lower parts of both lungs.

MDI: $69 \mathrm{mg} \cdot \mathrm{L}^{-1}$; HDI: $\left.95 \mathrm{mg} \cdot \mathrm{L}^{-1}\right)$. Intensification of therapy, as well as cessation of exposure, resulted in prompt improvement; however, in 2004, after short periods of re-exposure, the patient's condition worsened. She discontinued working completely in July 2004 and was examined in October 2004 by BGFA (Bochum, Germany).

The patient reported no improvement after cessation of exposure, despite an oral prednisolone dose of $10 \mathrm{mg} \cdot \mathrm{day}^{-1}$ and complained of mild cough with minor mucous phlegm production and shortness of breath after climbing a flight of stairs. However, flulike symptoms, nightly fever and fatigue had disappeared. Lung function showed mild restriction (VC 95\% pred; TLC 84\% pred) and $D \mathrm{~L}, \mathrm{CO} / V \mathrm{~A}$ was $35 \%$ pred. $\mathrm{Pa}, \mathrm{O}_{2}$ decreased from 69 to $56 \mathrm{mmHg}$ after exercising for $6 \mathrm{~min}$ on a treadmill at $50 \mathrm{~W}$. BAL yielded a total cell count of $2.1 \times 10^{5}$ cells $\cdot \mathrm{mL}^{-1}$ (recovery $80 \mathrm{~mL}$ ) with $44 \%$ lymphocytes, $49 \%$ macrophages, $7 \%$ granulocytes and a CD4/CD8 ratio of 0.14 . Elevated concentrations of specific IgG antibodies to diisocyanates were reproduced by BGFA, although at lower concentrations than the previous examination. The highest IgG antibody concentrations were measured for HDI, as described previously (TDI: $21 \mathrm{mg} \cdot \mathrm{L}^{-1}$, MDI: $49 \mathrm{mg} \cdot \mathrm{L}^{-1}$; HDI: $\left.68 \mathrm{mg} \cdot \mathrm{L}^{-1}\right)$. Total $\mathrm{IgG}$ was $12.2 \mathrm{~g} \cdot \mathrm{L}^{-1}$ (reference $7-16 \mathrm{~g} \cdot \mathrm{L}^{-1}$ ). Again, $\mathrm{IgG}$ concentrations to various moulds and acid anhydrides were not elevated.

IgG inhibition studies using the ImmunoCAP system with HDI, MDI or TDI as solid phase and HDI-human serum albumin (HSA), MDI-HSA and TDI-HSA ( 1 and $5 \mathrm{mg} \cdot \mathrm{mL}^{-1}$ ) as inhibitors showed that HDI-HSA was the best inhibitor (table 1). Cross-reactivity between all diisocyanates can be assumed. However, somewhat low auto-inhibition, especially in the case of TDI-HSA, shows some limitations, possibly due to different preparation sources of solid and liquid allergens.

A CT scan in October 2004 showed further improvement but there were still ill-defined centrilobular opacities with prevalence in the apical lung fields and patchy ground-glass pattern in the lower parts of both lungs. Discrete differences in bronchial wall thickness persisted (fig. 3). Follow-up examinations until June 2006 showed complete recovery of VC, but a slight reduction of $D \mathrm{~L}, \mathrm{CO} / V$ A persisted (fig. 1).

\section{EXPOSURE ASSESSMENT}

The shop employed $\sim 60$ males and modern spray paint booths were installed. The patient had no access to the booths but had to enter the workshop $\sim 10$ times per day for short time-periods. The patient's office was separated from the workshop by a 3-mlong corridor. The patient complained of an airstream from the workshop to her office. She was obviously at a low-exposure risk as there was no skin contact with isocyanates, and aerosol formation in the patient's breathing zone was not expected at the locations to which she had access. Thus, inhalational diisocyanate vapor exposure is the most likely exposure source.

The workshop used two-component polyurethane/acrylatesystems for coatings. The hardeners contained 25-50\% HDIhomopolymer and up to $1 \%$ HDI-monomer according to the material safety data sheets. In addition, MDI-containing 2-pack polyurethane adhesives or patching compounds were used regularly. Air sampling was carried out in June 2004 by the technical staff of the local statutory accident insurance and the quantitative analyses by BGIA (Sankt Augustin, Germany). Sampling of airborne diisocyanates was carried out in the patient's office, the corridor and in front of the booths while doors were kept closed (18 measurements in total). Both sampling and subsequent quantitative analyses were performed according to German standard procedures for the detection of airborne diisocyanates [6, 7]. Briefly, airborne vapours and aerosols were drawn through a sorption tube filled with glass wool, which was impregnated with $N$-(4-nitrobenzyl)-n-propylamine (nitroreagent) as a derivatisation reagent. During sample collection, diisocyanates react with nitroreagent to form corresponding soluble urea derivatives. Urea derivatives were eluted from the sampling tubes with dichloromethane immediately after sampling. Quantitative analysis was performed with high-performance liquid chromatography with UV detection. The limits of quantification were 3 and $2 \mu \mathrm{g} \cdot \mathrm{m}^{-3}$ for HDI and MDI, respectively. HDI was not found in any sample, but in one of the samples, a low concentration of MDI was detected ( $3 \mu \mathrm{g} \cdot \mathrm{m}^{-3}$, sampling in front of one booth). The chromatograms did not indicate any other monomeric or polymeric isocyanates, so the concentration of total reactive isocyanate groups was $1 \mu \mathrm{g} \cdot \mathrm{m}^{-3}$ in front of the spray paint booth, where MDI was detected. The nitrogen, carbon and oxygen (NCO) concentrations in the areas where the patient had access were $<1 \mu \mathrm{g} \cdot \mathrm{m}^{-3}$.

\section{DISCUSSION}

$\mathrm{HP}$ in this patient was documented by a typical history, a restrictive ventilation pattern, compatible radiographs/highresolution $\mathrm{CT}$, a typical BAL differential cell count with a low 


\begin{tabular}{|c|c|c|c|}
\hline $\begin{array}{ll}\text { TABLE } 1 & \text { Inhibition } \\
& \text { diisocya }\end{array}$ & iments n & the releve & \\
\hline \multirow{2}{*}{$\begin{array}{l}\text { Inhibitor concentration } \\
\mathrm{mg} \cdot \mathrm{mL}^{-1}\end{array}$} & \multicolumn{3}{|c|}{ Solid phase } \\
\hline & $\begin{array}{c}\text { HDI } \\
\text { inhibition }\end{array}$ & $\begin{array}{c}\text { MDI } \\
\text { inhibition }\end{array}$ & $\begin{array}{c}\text { TDI } \\
\text { inhibition }\end{array}$ \\
\hline \multicolumn{4}{|l|}{ HDI-HSA } \\
\hline 5 & 67 & 73 & 78 \\
\hline 1 & 31 & 46 & 44 \\
\hline \multicolumn{4}{|l|}{ MDI-HSA } \\
\hline 5 & 28 & 56 & 50 \\
\hline 1 & 14 & 20 & 33 \\
\hline \multicolumn{4}{|l|}{ TDI-HSA } \\
\hline 5 & 0 & 4 & 11 \\
\hline 1 & 0 & 0 & 0 \\
\hline \multicolumn{4}{|l|}{ HSA } \\
\hline 1 & 0 & 0 & 0 \\
\hline
\end{tabular}

Data are presented as \%. HDI: hexamethylene diisocyanate; MDI: methylenediphenyl diisocyanate; TDI: toluene diisocyanate; HSA: human serum albumin. \#: $10 \mu \mathrm{L}$ of the inhibitor solution was added to $50 \mu \mathrm{L}$ 1:100 diluted serum. Inhibition $<20 \%$ was considered not relevant.

CD4/CD8 ratio, and elevated diisocyanate-specific IgG antibody concentrations. A transbronchial lung biopsy is compatible with the diagnosis of sub-acute $\mathrm{HP}$, which seems to be an extremely rare disease, but is possibly often misdiagnosed [8].

The patient had been exposed to diisocyanates, known to cause HP since the 1970s [9]. A relationship between HP and the patient's occupation was demonstrated by high concentrations of diisocyanate-specific IgG antibodies in her serum and a clinical course (symptoms, diisocyanate-specific IgG antibody concentrations, radiographs/high-resolution CT and lung function) that was closely linked to exposure. Nonoccupational exposure to diisocyanates was denied. The patient did not recover completely after cessation of exposure. This does not argue against the diagnosis of $\mathrm{HP}$ as it is known from the literature that the outcome of sub-acute or chronic forms of HP is poor [10, 11]. Thus, there is virtually no doubt about a diagnosis of occupational $\mathrm{HP}$, which was categorised as subacute due to the available information.

Up to approximately four-fold elevated diisocyanate-specific IgG antibody concentrations were documented by two independent laboratories with the same method (Institute of Lung Diseases and Allergy, Bonn, Germany and BGFA). A cut-off for increased concentrations of $20 \mathrm{mg} \cdot \mathrm{L}^{-1}$, as recommended by the manufacturer, is used by both laboratories. It has been corroborated by the current authors in a small series of nonexposed control subjects (R. Merget, personal communication).

To the present authors' knowledge, no case-control studies have been performed that allowed an estimate of the importance of cross-reactive IgG antibodies to different diisocyanates in $\mathrm{HP}$, while cross-reactions between isocyanates have been reported in isocyanate asthma [12-14]. One case report of a car painter with HP described the existence of IgG antibodies to all three diisocyanates [15], whereas in another $\mathrm{HP}$ case IgG antibodies against polymeric MDI did not crossreact with TDI and HDI [16]. The exposure in the present case was mainly to HDI, but exposure to MDI also occurred. Exposure to TDI could not be documented at the patient's workplace. IgG inhibition experiments corroborated the interpretation that HDI is the primary sensitiser, although some cross-reactivity between diisocyanates was present. Relevant nonspecific binding to IgG can be excluded. Weak nonspecific binding to IgG in 12 out of 40 diisocyanate-exposed subjects with sensitisation to diisocyanates in the IgE system has been described previously [17]. The present case demonstrates that the measurement of diisocyanate-specific $\operatorname{IgG}$ antibodies is an appropriate tool for diagnosing HP.

It is known that HDI is dominant in frequency and exposure level in the car painting industry [18]. This assumption is corroborated by the inhibition experiments and the patient's IgG antibody response, which showed higher concentrations to HDI than to TDI and MDI. The origin of elevated MDI concentrations in one air sample could not be elucidated but may be a coating compound containing MDI that was used in the workshop.

Measurements of monomer concentrations in the air yielded detectable isocyanate concentrations in only a single sample in front of one booth, which was far below current exposure limits, e.g. $34 \mu \mathrm{g} \cdot \mathrm{m}^{-3}$ time-weighted average for HDI monomers [19]. Recently, a high number of isocyanate measurements were performed in 24 car body repair shops with the inclusion of monomers, oligomers and thermal degradation products [18]. In the present study, 28 measurements were also carried out in the offices of car body repair shops. Concerning HDI, 10 measurements were above the level of detection with a median concentration (range) of $0.04(0.001-0.13) \mu \mathrm{g} \cdot \mathrm{m}^{-3} \mathrm{NCO}$. In total, 16 measurements were carried out near drying areas; these yielded 12 samples above the level of detection with a median concentration (range) of $0.49(0.01-2.67) \mu \mathrm{g} \cdot \mathrm{m}^{-3} \mathrm{NCO}$. At both locations the concentrations were much lower than concentrations near the spray painting. Out of four measurements, three were above the level of detection with a median concentration (range) of $10.47(0.07-10.48) \mu \mathrm{g} \cdot \mathrm{m}^{-3}$ NCO. These results are plausible and indicate that the patient's exposure was far below current exposure limits, which were set, for example, in Sweden or the UK at $20 \mu \mathrm{g} \cdot \mathrm{m}^{-3}$ time-weighted average (as NCO groups).

The present case indicates that sub-acute or chronic occupational hypersensitivity pneumonitis may be induced by low isocyanate levels. This has consequences both for prevention and diagnosis [20]. There is also an impact on the diagnosis of interstitial lung diseases beyond hypersensitivity pneumonitis because a chronic clinical course in subjects without known occupational risk may obscure the correct diagnosis.

\section{REFERENCES}

1 Bakke JE, Olof Norén J, Thorud S, Aasen TB, eds, International Consensus Report on: Isocyanates - Risk assessment and management. November 20-22, 2001, 
Furnes, Norway. www.arbeidstilsynet.no/binfil/download. php?tid=27871 Date last accessed: June 22, 2008.

2 Baur X. Hypersensitivity pneumonitis (extrinsic allergic alveolitis) induced by isocyanates. J Allergy Clin Immunol 1995; 95: 1004-1010.

3 Vandenplas O, Malo JL, Dugas M, et al. Hypersensitivity pneumonitis-like pneumonitis reaction among workers exposed to diphenylmethane [correction to pipheylmethane] diisocyanate (MDI). Am Rev Respir Dis 1993; 147: 338-346.

4 Bernstein DI, Korbee L, Stauder T, et al. The low prevalence of occupational asthma and antibody-dependent sensitization to diphenylmethane diisocyanate in a plant engineered for minimal exposure to diisocyanates. J Allergy Clin Immunol 1993; 92: 387-396.

5 Quanjer PH, Tammeling GJ, Cotes JE, Pedersen OF, Peslin R, Yernault JC. Lung volumes and forced ventilatory flows. Report Working Party Standardisation of Lung Function Tests, European Community for Steel and Coal. Official Statement of the European Respiratory Society. Eur Repir J 1993; 6: Suppl. 16, 5-40.

6 Hahn JU, Assenmacher-Maiworm H. Isocyanates. In: BG Institute for Occupational Safety and Health, ed. BGIAArbeitsmappe - Messung von Gefahrstoffen. [BGIA workbook measurements of hazardous substances.] Erich Schmidt, Berlin, 1989; Suppl. 47, 7670.

7 Tiesler A, Eben A. Hexamethylene diisocyanate (HDI), 2,4and 2,6-Toluylene diisocyanate (TDI; toluene-2,4- and 2,6diisocyanate). In: Deutsche Forschungsgemeinschaft Commission for the Investigation of Health Hazards of Chemical Compounds in the Work Area, ed. Analyses of Hazardous Substances in Air. Volume 1. New York, Wiley and Sons, 1991; pp. 67-83.

8 Yoshizawa Y, Ohtani Y, Hayakawa H, Sato A, Suga M, Ando M. Chronic hypersensitivity pneumonitis in Japan: a nationwide epidemiologic survey. J Allergy Clin Immunol 1999; 103: 315-320.

9 Charles J, Bernstein A, Jones B, et al. Hypersensitivity pneumonitis after exposure to isocyanates. Thorax 1976; 31: 127-136.

10 Zacharisen MC, Schlueter DP, Kurup VP, Fink JN. The long-term outcome in acute, subacute, and chronic forms of pigeon breeder's disease hypersensitivity pneumonitis Ann Allergy Asthma Immunol 2002; 88: 175-182.

11 Akimoto T, Tamura N, Uchida K, Dambara T, Nukiwa T, Kira S. [A case of hypersensitivity pneumonitis due to isocyanate exposure showing progression even two months after removal of the antigen.]. Nihon Kyobu Shikkan Gakkai Zasshi 1992; 30: 458-463.

12 Grammer LC, Harris KE, Malo JL, Cartier A, Patterson R. The use of an immunoassay index for antibodies against isocyanate human protein conjugates and application to human isocyanate disease. J Allergy Clin Immunol 1990; 86: 94-98.

13 Baur X. Immunologic cross-reactivity between different albumin-bound isocyanates. J Allergy Clin Immunol 1983; 71: 197-205.

14 Innocenti A, Cirla AM, Pisati G, Mariano A. Cross reactions between aromatic isocyanates (TDI and MDI): a specific bronchial provocation test study. Clin Allergy 1988; 18: 323-329.

15 Suzuki N, Matsuzaki G, Arai Y, et al. [A case of hypersensitivity pneumonitis in which serum specific antibodies for three species of isocyanate molecules were demonstrated.]. Nihon Kyobu Shikkan Gakkai Zasshi 1992; 30: 478-484.

16 Aul DJ, Bhaumik A, Kennedy AL, Brown WE, Lesage J, Malo JL. Specific IgG response to monomeric and polymeric diphenylmethane diisocyanate conjugates in subjects with respiratory reactions to isocyanates. J Allergy Clin Immunol 1999; 103: 749-755.

17 Baur X, Chen Z, Flagge A, Posch A, Raulf-Heimsoth M. EAST and CAP specificity for the evaluation of $\operatorname{IgE}$ and IgG antibodies to diisocyanate-HSA conjugates. Int Arch Allergy Immunol 1996; 110: 332-338.

18 Pronk A, Tielemans E, Skarping G, et al. Inhalation exposure to isocyanates of car body repair shop workers and industrial spray painters. Ann Occup Hyg 2006; 50: 1-14.

19 Health and Safety Executive, EDS. Isocyanates: Health Hazards and Precautionary Measures. Guidance Note EH 16. Suffolk, HSE Books, 1999.

20 Sennekamp J, ed, Extrinsic Allergic Alveolitis. Hypersensitivity Pneumonitis. Munich, Orlando, Dustri Verlag, 2004. 